\title{
Comparison between a two-stage and single-stage digesters when treating a synthetic wastewater contaminated with phenol
}

\author{
JE Hernandez ${ }^{1,2 *}$ and RGJ Edyvean ${ }^{2}$ \\ ${ }^{1}$ Institute for Biotechnology and Bioengineering, Centre for Biological Engineering, UMINHO, Campus Gualtar, \\ 4710-057 Braga, Portugal \\ ${ }^{2}$ Department of Chemical and Process Engineering, University of Sheffield, Broad Lane, Sheffield, S3 7HQ, United Kingdom
}

\begin{abstract}
Phenol is a pollutant found in many industrial wastewaters, which diminishes biogas formation in anaerobic digesters. In this study, a two-stage (acidogenic and methanogenic) anaerobic digester (TSAD) was compared to a single stage digester (SSD), in treating a synthetic wastewater contaminated with phenol. Both systems were operated in batch-dilution and semi-continuously at $35^{\circ} \mathrm{C}$, and were loaded with a synthetic wastewater containing a constant concentration of readily biodegradable organic matter and an increasing concentration of phenol. The TSAD had greater biogas production, and its acidogenic reactor fermented the readily biodegradable matter without inhibition by accumulation of phenol (up to 1450 $\left.\mathrm{mg} \cdot \ell^{-1}\right)$. The acidogenic reactor also prevented inhibition of biogas formation in the second phase (methanogenic), by holding phenol and fast produced organic acids. Batch TSAD is a potential wastewater treatment option to decontaminate streams containing readily biodegradable matter contaminated with phenol. This system enhances biogas production and allows better control of the acidogenic and methanogenic phases.
\end{abstract}

Keywords: Acidogenic, biodegradation, biogas, industrial waste, methanogenic, phenol, two-phase anaerobic digestion

\section{Introduction}

Phenol is mainly derived from oil and coal and is used in the production of fertilisers, fungicides, dyes, plastics, solvents and fibre board (Veeresh et al., 2005). The global production of phenol surpassed $6.6 \times 10^{6} \mathrm{t}$ in 2000; it is mainly manufactured in Europe and the USA (Niwa et al., 2002; Panov, 2000). Phenol is a priority pollutant and the latest figure shows that $3480 \mathrm{t}$ were released into the USA environment in 2005 (USEPA, 2008). A maximum concentration of $17000 \mathrm{mg} \cdot \ell^{-1}$ in wastewater has been reported (Veeresh et al., 2005).

The elimination of phenol in wastewater has been studied by applying several physicochemical and biological technologies, with a variety of operational designs and combinations. However, anaerobic digestion still remains the most attractive option (Veeresh et al., 2005). A major drawback is that at certain concentrations phenol can disturb the trophic chain established between microorganisms, by affecting the production of fatty acids, hydrogen and thus methane (Fedorak and Hrudey, 1984; Wang et al., 1989; Hernandez and Edyvean, 2008). Phenol biomethanisation has been studied in a variety of single-phase anaerobic digesters (Veeresh et al., 2005). Nevertheless, the application of two-phase anaerobic digestion (TSAD), consisting of acidogenic and subsequent methanogenic steps, is largely unexplored. In addition, the inhibitory effects of phenol on the TSAD are not known.

The advantages of TSAD over a single-stage digester (SSD) are well recognised. TSAD reduces toxicity to methanogenesis

\footnotetext{
* To whom all correspondence should be addressed. New address: School of Chemical Engineering and Analytical Science, University of Manchester, Oxford Road, Manchester, M13 9PL, United Kingdom

? e-mail: cpp02jeh@yahoo.com.mx

Received 1 August 2008; accepted in revised form 5 November 2010.
}

by hosting fast growing acidogens in a separate reactor, thus preventing trophic-chain imbalances due to both the high rate of production of volatile fatty acids (VFAs), and their low rate conversion by methanogens (Tchobanoglous et al., 2003). In addition, TSAD allows the dilution of the VFAs produced in the acidogenic phase before being loaded into the methanogenic reactor, avoiding the utilisation of sources of freshwater for dilution. Some findings show that the acidogenic phase enhanced the biodegradability of aromatic ring molecules such as nitrobenzene and flavonoids (Herrmann and Janke, 2001; Ng et al., 1999).

In this study, the aim was to compare the treatment of a synthetic wastewater containing a readily biodegradable matter and phenol, when performed in a TSAD and SSD. Performance of both TSAD and SSD was studied at dilution-batch and semicontinuous operation. The results of this study address the question as to whether continuous or batch TSAD is the best option for treating a wastewater contaminated with phenol.

\section{Materials and methods}

\section{Materials}

Anaerobic reactors were constructed with glass 'quick fit' vessels fitted with a multi-socket top (Fig. 1). The TPAD was composed of an acidogenic (R1) and a methanogenic reactor (R2). The SSD was a methanogenic reactor similar to R2. All reactors had $4 \ell$ of reaction volume and were magnetically stirred and submerged in water baths at $35^{\circ} \mathrm{C}$. R2 and SSD were filled with a commercial rigid packing design (Flocor, UK) to support the growth of fermenting methanogenic consortia. The produced biogas was collected and measured in graduated cylinders (approx. $101.325 \mathrm{kPa}$ and $25^{\circ} \mathrm{C}$ ), whose tops were submerged downwards into a barrier solution to avoid the loss of $\mathrm{CO}_{2}$ (DIN, 1985); the prototype is shown in Fig. 4. pH was recorded by a portable temperature compensated $\mathrm{pH}$ meter. 


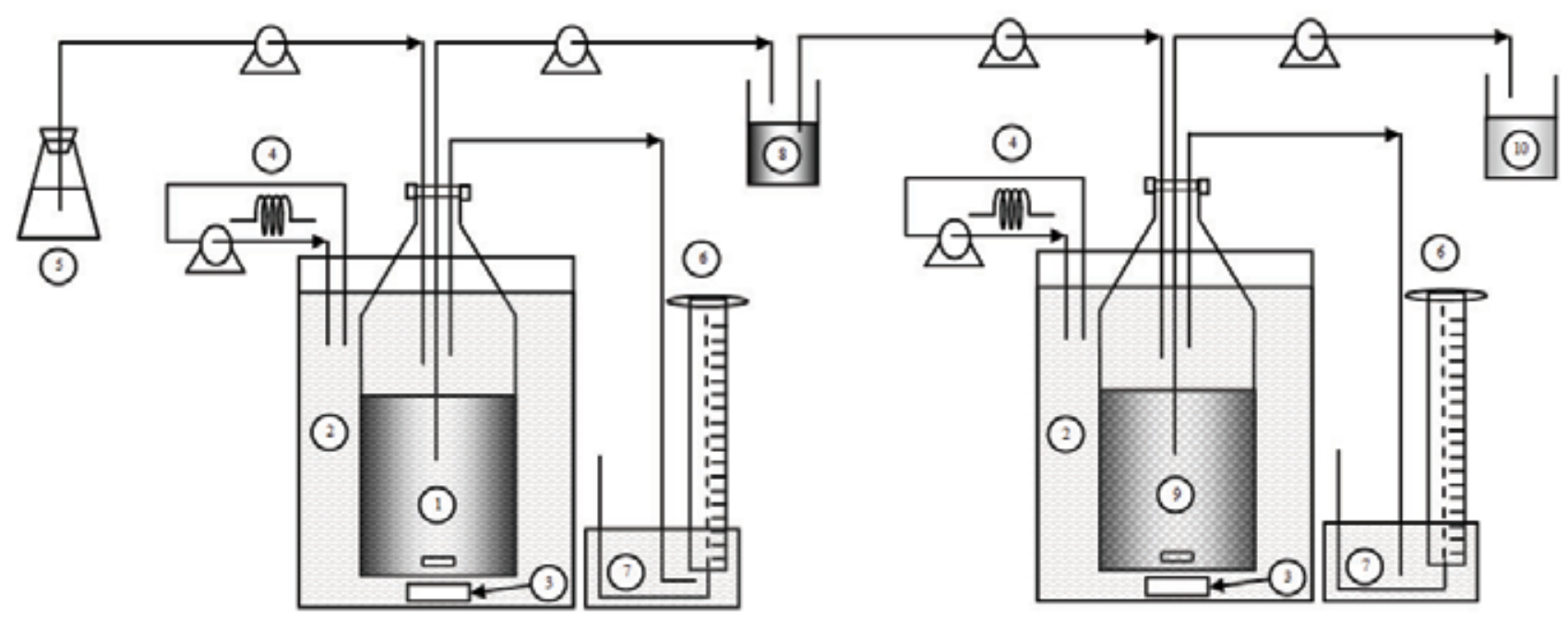

Figure 1

Two stage anaerobic digester. Identifiers: 1. Acidogenic reactor (R1); 2. Water bath $\left(35^{\circ} \mathrm{C}\right)$;

3. Immersed magnetic stirrer; 4. Temperature controller; 5. Buffered synthetic waste waster;

6. Gas collector; 7. Barrier solution; 8. Fermented effluent from $R 1$ to feed into R2;

9. Methanogenic reactor (R2); 10. Effluent from R2. The SSD was similar in design to R2.

A buffer solution made of $7.5 \mathrm{~g} \mathrm{NaOH} / 10 \mathrm{~g} \mathrm{NaHCO}_{3}$ was used to control $\mathrm{pH}$.

A commercial nutritional supplement (NS), containing readily biodegradable matter, was obtained from Boots, Co. (Table 1), while phenol and other chemicals were obtained from Sigma-Aldrich, Co. Synthetic Wastewater 1 (SWW1) was a mixture of phenol (50 to $\left.250 \mathrm{mg} \cdot \ell^{-1}\right)$ and the medium given in ISO 11734 (CEN, 1999). Synthetic Wastewater 2 (SWW2) was prepared by mixing phenol and NS (Table 1).

Digesting sludge was obtained from an anaerobic digester treating yeast and industrial wastewater. It was mesh sieved (1 $\mathrm{mm}^{2}$ ) and utilised to produce acidogenic and methanogenic sludge.

\section{Analysis}

Liquid samples were taken and stored following standard methods (APHA, 1998). Chemical analyses to the liquid fraction were carried out with the following Dr Lange ${ }^{\circledR}$ cuvette test kits: LCK 384 Total organic carbon (TOC), LCK 114 chemical oxygen demand (COD), LYW 365 organic acids (VFAs) and LCK 346 phenols. Volatile suspended solids (VSS) were determined by standard methods (APHA, 1998). The suspended fraction of COD and TOC (i.e. SCOD and SOC) were calculated after separating the dissolved fraction through a $0.45 \mu \mathrm{m}$ pore diameter fibreglass filter. $\mathrm{CH}_{4}$ and $\mathrm{CO}_{2}$ in the biogas were analysed using a gas chromatograph (GC, Varian 3400) fitted with a methaniser. The capillary column ( $30 \mathrm{~m} \times 0.530 \mathrm{~mm}$ GS-Q) was packed with $10 \%$ nickel nitrate on Chromosorb GAW 100/120. It operated at $60^{\circ} \mathrm{C}$ and inlet pressure of $39.3 \mathrm{kPa}$. The injector and flame ionisation detector operated at $350^{\circ} \mathrm{C}$ and $280^{\circ} \mathrm{C}$, respectively. Nitrogen gas was used as a carrier gas (19.0 $\mathrm{cm} \cdot \mathrm{s}^{-1}$ ). Gas concentrations, including $\mathrm{CO}_{2}$ and $\mathrm{CH}_{4}$ dissolved in aqueous phase, were corrected by applying Henry's Law as reported (Hernandez and Edyvean, 2008). Methane-rich gas in $\mathrm{R} 2$ and SSD is referred as biogas throughout the text.

\section{Acclimation of methanogenic sludge to phenol}

Three reactors were separately inoculated with sludge $\left(3.6 \ell, \mathrm{VSS}=18.9 \mathrm{~g} \cdot \ell^{-1}\right)$ and loaded with $0.4 \ell$ of SWW1, which

\begin{tabular}{|c|c|}
\hline \multicolumn{2}{|c|}{$\begin{array}{c}\text { Table } 1 \\
\text { Features of the synthetic wastewater made with } \\
\text { phenol, nutritional supplement (NS) and distilled } \\
\text { water (Substrate 2) }\end{array}$} \\
\hline \multicolumn{2}{|c|}{ Wastewater characteristics } \\
\hline Parameter & Measure \\
\hline $\mathrm{pH}$ & 6.85 \\
\hline $\mathrm{COD}^{\mathrm{a}}$ & 9.7 \\
\hline From NS & 7.3 \\
\hline From phenol & 2.4 \\
\hline \multicolumn{2}{|l|}{ NS composition } \\
\hline Typical Values & Per $100 \mathrm{~g}$ powder ${ }^{\mathrm{b}}$ \\
\hline Energy value & $1552 \mathrm{~kJ}$ \\
\hline Protein & 20 \\
\hline Carbohydrate & 68 \\
\hline Of which sugars & 55 \\
\hline Fat & 1.5 \\
\hline Of which saturates & 1.0 \\
\hline Fibre & 1.0 \\
\hline Sodium & 0.4 \\
\hline Vitamins and minerals & Per 100 g powder ${ }^{c}$ \\
\hline Vitamin A & 533 \\
\hline Vitamin D & 3.3 \\
\hline Vitamin E & $10 \times 10^{3}$ \\
\hline Vitamin C & $3.3 \times 10^{3}$ \\
\hline Thiamin (Vitamin B) & $0.9 \times 10^{3}$ \\
\hline Riboflavin (Vitamin B & $1.1 \times 10^{3}$ \\
\hline Niacin & $12 \times 10^{3}$ \\
\hline Vitamin B & $12 \times 10^{3}$ \\
\hline Folic acid ${ }^{\sigma}$ & 133 \\
\hline Vitamin B & 0.7 \\
\hline Biotin 12 & $0.1 \times 10^{3}$ \\
\hline Panthotenic acid & $4.0 \times 10^{3}$ \\
\hline Calcium & 770 \\
\hline Phosphorus & 522 \\
\hline Iron & 9.3 \\
\hline $\mathrm{Mg}$ & $115 \times 10^{3}$ \\
\hline $\mathrm{Zn}$ & $10 \times 10^{3}$ \\
\hline $\mathrm{I}$ & $100 \times 10^{3}$ \\
\hline
\end{tabular}

Available on website http://www.wrc.org.za ISSN 0378-4738 (Print) = Water SA Vol. 37 No. 1 January 2011 ISSN 1816-7950 $($ On-line $)=$ Water SA Vol. 37 No. 1 January 2011 
contained only phenol as a carbon source. Initially, the reactors contained $50 \mathrm{mg}$ phenol $\cdot \ell^{-1}$. After complete elimination of phenol (6 d), a settling period of $3 \mathrm{~h}$ was allowed; subsequently the supernatant was drawn off. The whole cycle was repeated at 100 and then at $250 \mathrm{mg}$ phenol $\ell^{-1}$, respectively, with the aim of gradually increasing the number of phenol degraders. Two final cycles at $250 \mathrm{mg}$ phenol $\ell^{-1}$ were run to stabilise conditions. In these final cycles, the average biogas produced in each reactor was $369 \pm 4 \mathrm{m \ell}\left(65 \pm 2.8 \% \mathrm{CH}_{4}\right)$ Methanogenesis was not observed in autoclaved inactivated sludge with (i.e. controls) and without (i.e. blanks) phenol. Methanogenesis was insignificant in controls containing medium and active sludge, and inexistent in blanks containing medium and phenol.

\section{Production of acidogenic sludge}

R1 was inoculated with acclimatised methanogenic sludge $\left(\mathrm{VSS}=18.9, \mathrm{~g} \cdot \ell^{-1}\right)$ and loaded with SWW2, which contains readily biodegradable matter and phenol. Initially, R1 contained $25 \mathrm{mg}$ phenol $\cdot \ell^{-1}$ and $1.83 \mathrm{~g} \mathrm{DCOD} \cdot \ell^{-1}$ (DCOD is dissolved chemical oxygen demand). This DCOD load was in the range of previously reviewed values for TPAD (Demirel and Yenigun, 2002). After $24 \mathrm{~h}$, the $\mathrm{pH}$ dropped due to fast production of organic acids, which were partially removed by settling the sludge down for $3 \mathrm{~h}$ and removing the supernatant. R1 was reloaded with SWW2 and adjusted with buffer to $\mathrm{pH} 5.5$ twice a day. The batch cycle was serially repeated until the sludge became yellowish-brown in colour, this being an indication of disrupted methanogenesis (Demirel and Yenigun, 2002). The lack of methane formation was also confirmed by GC analysis.

\section{Batch-dilution elimination of phenol}

Two separated reactors formed the TSAD (R1 and R2). The SSD was similar to R2. In total, 4 consecutive batches were double run, and the concentration of phenol ( 25 to $\left.250 \mathrm{mg} \cdot \ell^{-1}\right)$ was increased between batches while keeping constant the complementary DCOD within SWW2. On the first run of Batch 1, both $\mathrm{R} 1$ and the SSD were loaded with SSW2, and operated at initial concentration of $25 \mathrm{mg}$ phenol $\cdot \ell^{-1}$ and $1.83 \mathrm{~g} \mathrm{DCOD} \cdot \ell_{\mathrm{R}}^{-1}$.

$\mathrm{R} 2$ is fed with R1 effluent and, therefore, after $1 \mathrm{~d}$ (approximate time to eliminate phenol in R2) $400 \mathrm{~m} \ell$ of liquor was pumped out from $\mathrm{R} 1, \mathrm{pH}$ adjusted and then fed into $\mathrm{R} 2$. The missing volume in $\mathrm{R} 1$ was replenished with acidogenic sludge. To allow for comparison, the same volume was drawn from the SSD and replenished with methanogenic sludge (prepared as described earlier). Adjustment of $\mathrm{pH}$ was done twice a day at 5.5 in R1 and 8.5 in both R2 and SSD, aiming at promoting acidogenic and methanogenic conditions, respectively.

The whole procedure was repeated daily until the concentration of phenol was undetectable in R1 and SSD. Afterwards, the sludge was settled for $3 \mathrm{~h}$ and the supernatant drawnoff, this was the end of a single run and the whole cycle was repeated at the same conditions for a second run. At the end of Batch 4, the reactors were left standing for $1 \mathrm{~d}$ and then were semi-continuously operated.

\section{Semi-continuous elimination of phenol}

This experiment was carried out semi-continuously for $15 \mathrm{~d}$. R1 and SSR were daily refilled with substrate SWW2 (9.7 g COD; Table 1). Every day, $400 \mathrm{~m} \ell$ of liquid was pumped out of each reactor. The effluent of $\mathrm{R} 1$ was $\mathrm{pH}$-adjusted and fed into $\mathrm{R} 2$, whereas the effluent from the SSR was discarded. $\mathrm{pH}$ was controlled as described above. In this operational mode, the remaining volume in R1 and SSR was increased up to $4 \ell$ with the daily feed of substrate and buffer.

\section{Results and discussion}

\section{Batch-dilution elimination of phenol}

In R1, fast fermentation of the readily organic fraction in SWW2 was observed, as will normally occur in acidogenic reactors where methanogens have been largely eliminated. Part of the phenol in SWW2 was lost, probably due to adsorption onto sludge, as evaluated in blanks and controls, and not converted to gas products. It can be seen that the experimental values of phenol concentration describe a curve that closely approximates calculated concentrations due to daily dilution (Fig. 2). On this basis, the difference between both experimental and calculated concentration plots cannot be linked to biodegradation, but can be attributed either to experimental errors or to adsorption of phenol onto the sludge. In some cases, up to $40 \%$ adsorption
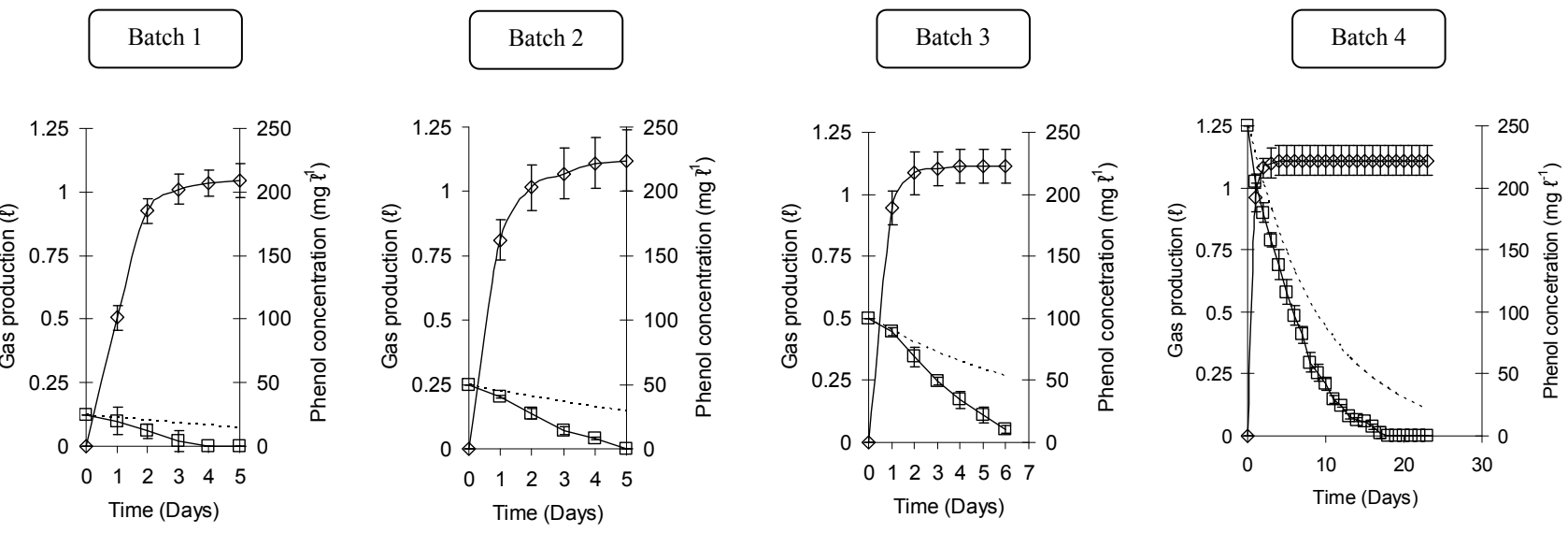

Figure 2

Elimination of phenol in R1 during the batch operation of TPAD; $400 \mathrm{ml}$ was pumped out of R1 and fed in R2, with 2 runs per batch. Both systems were operated without adding substrate. The missing volume in R1 was replenished with acidogenic sludge without adding fresh substrate. The dashed line represents the calculated concentration of phenol due to dilution (0.9 times the concentration of the day before). Markers: concentration

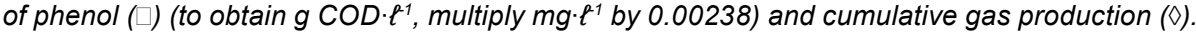




\begin{tabular}{|c|c|c|c|c|c|c|c|c|}
\hline \multicolumn{9}{|c|}{$\begin{array}{c}\text { Table } 2 \\
\text { Comparison of the performance of the TPAD and SSR in batch-dilution operation. The time for elimination } \\
\text { of phenol in the TPAD was limited by R1, where phenol may not be biodegraded. Phenol elimination in R2 } \\
\text { and SSR started without lag phase. Biogas production, methane composition and biogas productivity } \\
\text { correspond to R2 and SSR. }\end{array}$} \\
\hline \multirow[b]{2}{*}{$\begin{array}{c}\mathrm{C}_{0}^{\mathrm{a}} \\
\left(\mathrm{mg} \mathrm{e}_{\mathrm{R}}^{-1}\right)\end{array}$} & \multicolumn{4}{|c|}{\begin{tabular}{|l|} 
TPAD \\
\end{tabular}} & \multicolumn{4}{|c|}{ SSR } \\
\hline & $\begin{array}{l}\text { Time for } \\
\text { elimination b } \\
\text { (d) }\end{array}$ & $\begin{array}{c}\text { Biogas } \\
\text { Production } \\
\text { (l) }\end{array}$ & $\% \mathrm{CH}_{4}$ & \begin{tabular}{|c|} 
Biogas \\
productivity \\
$\left(\ell\left(\ell_{\mathrm{P}} \mathrm{d}\right)^{-1}\right)$
\end{tabular} & $\begin{array}{c}\text { Time for } \\
\text { elimination d } \\
\text { (d) }\end{array}$ & $\begin{array}{c}\text { Biogas } \\
\text { Production } \\
\text { (e) }\end{array}$ & $\% \mathrm{CH}_{4}$ & $\begin{array}{c}\text { Biogas } \\
\text { productivity } \\
\left(\ell\left(\ell_{\mathrm{B}} d\right)^{-1}\right)\end{array}$ \\
\hline 25 & 4 & $3.3 \pm 0.2$ & $66 \pm 2$ & $0.21 \pm 0.011$ & 5 & $0.90 \pm 0.12$ & $47 \pm 3$ & $0.045 \pm 0.006$ \\
\hline 50 & 5 & $3.5 \pm 0.1$ & $67 \pm 1$ & $0.17 \pm 0.006$ & 5 & $1.14 \pm 0.13$ & $52 \pm 1$ & $0.057 \pm 0.006$ \\
\hline 100 & 7 & $4.3 \pm 0.0$ & $65 \pm 2$ & $0.15 \pm 0.001$ & 6 & $1.43 \pm 0.08$ & $49 \pm 2$ & $0.060 \pm 0.003$ \\
\hline 250 & 18 & $5.8 \pm 0.2$ & $66 \pm 2$ & $0.08 \pm 0.003$ & 7 & $1.72 \pm 0.09$ & $48 \pm 2$ & $0.062 \pm 0.003$ \\
\hline
\end{tabular}

${ }^{a} C_{0}$ is the initial concentration of phenol in both TPAD and SSR. To obtain $g$ COD $\ell^{-1}$, multiply this column by 0.00238 .

${ }^{b}$ This is the time required to eliminate phenol from $R 1$ and $S S R$.

${ }^{c}$ Biogas production is the total cumulative gas production in $R 2$ and SSR at the end of each batch cycle.

${ }^{d}$ Biogas productivity is calculated in the exponential phase of biogas production in methanogenic reactors $R 2$ and SSR.

has been reported (Healy and Young, 1979; Hernandez and Edyvean, 2008). Therefore, phenol was not biodegraded in R1 but diluted and disposed of due to filling and draw.

Phenol biodegradation occurred in the acclimatised digesting sludge used as initial inoculum. However, in R1, phenol mineralisation is thermodynamically limited due to lack of syntrophism between fast-fermenting microorganisms and the deliberately disturbed methanogens. Thermodynamically, this association is necessary to favour aromatic ring fission to produce acetate and hydrogen, which are subsequently utilised by methanogens to produce biogas (Thauer et al., 1977; Winter and Knoll, 1989). Phenol fermentation can also be impeded due to its highly effective inhibition effects on the electron transport and energy production of phenol degraders (Escher et al., 1996; Fedorak and Hrudey, 1984; Wang et al., 1989). R1 is therefore not effective in breaking the aromatic ring but it may enhance the biodegradability of phenol by modifying the molecule, as occurred in similar experiments with acidogenic reactors (Herrmann and Janke, 2001; Karlsson et al., 2000; Ng et al., 1999).

The gas produced in $\mathrm{R} 1\left(1.1 \pm 0.07 \ell, 99.98 \% \mathrm{CO}_{2}\right.$, not considering $\mathrm{H}_{2}$ and VFAs) is likely to come from the fermentation of readily biodegradable matter into VFAs (Fig. 2). In this reactor, increasing the concentration of phenol did not affect the production of gas, meaning that the fermentation of organic matter in SSW2 is not inhibited. This advantageous feature could be useful for the pre-treatment of waste streams containing a readily biodegradable matter mixed with phenol.

Biogas production $(\ell)$ and biogas productivity $\left(\ell\left(\ell_{R} d\right)^{-1}\right)$ were always higher in the TSAD at the end of each batch cycle (Table 2). Increasing phenol concentration increased both the time required for phenol elimination and the biogas production in both TPAD and SSD. Therefore, this operation affected biogas productivity differently. For instance, productivity decreased in the TPAD (longer time batch cycles) but increased in the SSR (shorter time batch cycles).

The methane composition in the biogas produced by the SSD was initially $59 \pm 2 \%$ when SSW1 was fed. In this reactor, swapping to SSW2 caused a delay in phenol elimination (5 d) when compared to the TSAD (Table 2). This probably occurred because the bulk matter in SSW2 was easily fermented by fastgrowing acidogenic bacteria into organic acids, consequently causing an imbalance with slow-growing methanogens. As the operation continues, SSD overcame the imbalances and biologically eliminated higher loads of phenol faster than the TSAD. Such recovery of methanogenic activity might be due to repeated replenishment with fresh methanogenic sludge already adapted to phenol.

In the TSAD, a fraction of phenol and organic acids from $\mathrm{R} 1$ was biomethanised in $\mathrm{R} 2\left(67 \% \mathrm{CH}_{4}\right.$ and $\left.33 \% \mathrm{CO}_{2}\right)$, as would normally occur in anaerobic digesters. Such fraction of phenol was completely eliminated every day, in R2, by the parallel participation of biomethanisation, adsorption onto the sludge and cell mass assimilation (Healy and Young, 1979; Hernandez and Edyvean, 2008). Methanogenic conditions in R2 were superior because the effluent $(400 \mathrm{~m} \ell)$ taken from R1 (containing phenol, organic acids and acidogens) was diluted within the total R2 volume, and shock due to overloading or inhibition was therefore avoided. The longer times required to eliminate phenol by dilution in R1 allowed more loadings into R2. Logically, more biogas was produced at the expense of longer periods of time, causing a reduction in biogas productivity $\left(\ell\left(\ell_{R} d\right)^{-1}\right)$.

\section{Semi-continuous elimination of phenol}

The lack of phenol biodegradability and its daily feeding into R1 caused accumulation (Fig. 3). As explained before, the biodegradation of phenol was hampered due to the thermodynamic and ecotoxicological limitations established in R1, so the

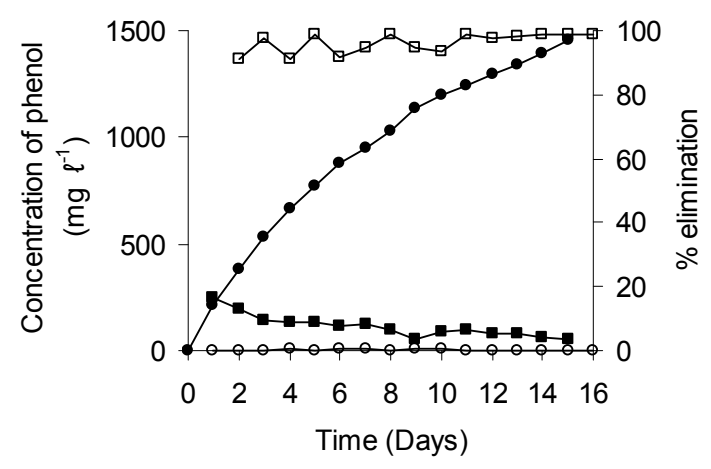

Figure 3

Concentration of phenol and percentage of elimination in semicontinuous operation. $\bullet$ Phenol concentration in the acidogenic reactor (R1) (To obtain $g$ COD $\ell^{-1}$, multiply $m g \cdot \ell^{-1}$ by 0.00238 );

- Phenol concentration in the methanogenic reactor (R2);

- Percentage of phenol elimination in R1; $\square$ Percentage of phenol elimination in $R 2$. 


\begin{tabular}{|c|c|c|c|c|}
\hline \multicolumn{5}{|c|}{$\begin{array}{c}\text { Table } 3 \\
\text { Comparison of the performance of the TSAD and SSR in semi-continuous operation }\end{array}$} \\
\hline \multirow{3}{*}{ Parameter } & & \multicolumn{3}{|c|}{ Reactor } \\
\hline & & \multicolumn{2}{|c|}{ TPAD } & \multirow[t]{2}{*}{ SSR } \\
\hline & & R1 & R2 & \\
\hline Gas productivity & $\left(\ell\left(\ell_{\mathrm{R}}^{-1} \mathrm{~d}^{-1}\right)\right)$ & $0.28 \pm 0.01$ & $0.8 \pm 0.02$ & $0.26 \pm 0.01$ \\
\hline $\mathrm{CH}_{4}$ & $(\%)$ & $0.02 \pm 0.01$ & $59 \pm 1.86$ & $0.09 \pm 0.03$ \\
\hline $\mathrm{pH}$ & & $5.60 \pm 0.04$ & $8.4 \pm 0.03$ & 8.5 to 4.3 \\
\hline Buffer volume & $(\mathrm{m} \ell \mathrm{NaOH} / \mathrm{NaHCO})_{3}$ & $25.80 \pm 3.20$ & $17.8 \pm 1.30$ & 21 to 41 \\
\hline DCOD & $\left(\mathrm{g} \cdot \ell^{-1}\right)$ & $23.13 \pm 0.37$ & $0.66 \pm 0.04$ & $28.79 \pm 1.59$ \\
\hline DCOD degraded & $(\%)$ & $-0.30 \pm 1.98$ & $76.85 \pm 1.09$ & $-0.015 \pm 0.01$ \\
\hline Organic acids (OA) & $\left(\mathrm{g}\right.$ acetic acid $\left.\cdot \ell^{-1}\right)$ & $6.60 \pm 0.28$ & $0.314 \pm 0.02$ & $5.1 \pm 0.81$ \\
\hline OA conversion $^{\mathrm{a}, \mathrm{b}}$ & $(\%)$ & $36.70 \pm 2.01^{a}$ & $68.74 \pm 2.35^{b}$ & $19.48^{\mathrm{a}} \pm 1.23$ \\
\hline SOC & $\mathrm{g} \mathrm{SOC} \cdot \ell^{-1}$ & $2.70 \pm 0.09$ & 0.0002 to 0.14 & $1.94 \pm 0.11$ \\
\hline $\begin{array}{l}\text { Notes: } \\
\text { a Produced from acidog } \\
{ }^{b} \text { Degraded in methanog } \\
\text { N/A: Not applicable }\end{array}$ & $\begin{array}{l}\text { esis } \\
\text { nesis }\end{array}$ & & & \\
\hline
\end{tabular}

losses of phenol might be attributed to physical interactions, e.g. adsorption onto sludge as evaluated in blanks and controls (Hernandez and Edyvean, 2008).

The maximum concentration of phenol reached in R1 was 1 $450 \mathrm{mg} \cdot \ell^{-1}$, from which $400 \mathrm{~m} \ell$ was transferred for subsequent treatment in R2. Since phenol was diluted within the whole R2 working volume, its concentration was far below $1250 \mathrm{mg} \cdot \ell^{-1}$, which may promote $50 \%$ inhibition of acetate methanogenesis (Wang et al., 1991). This capacity of preventing shock loading to the methanogenic reactor can reduce the vulnerability against unexpected increments of phenol and other organic matter in wastewater streams. However, accumulation is not desirable in a process receiving regular inputs of wastewater. Therefore, the continuous operation of a TSAD treating a wastewater containing phenol may not be acceptable.

Gas production was stable in R1 and R2 over the experiment. The gas produced in $\mathrm{R} 1\left(99 \% \mathrm{CO}_{2}\right.$, disregarding $\mathrm{H}_{2}$ and volatile organics) was derived from the fermentation of readily biodegradable matter in SSW2 and not from phenol. On the other hand, R2, which is the TSAD second stage, produced 3 times more biogas with a richer $\mathrm{CH}_{4}$ content than the SSD (Table 3 ). The biogas production capacity in the SSD was disturbed after $24 \mathrm{~h}$ of starting the operation. Probably, the daily feeding of SSW2 led to fast growth of acidogens, as commonly happens in acidogenic reactors fed with readily biodegradable matter (Demirel and Yenigun, 2002). Consequently, the SSD failed to produce methane and eliminate phenol. Therefore, further analysis of the SSD was stopped at this stage of the experiment.

Stable control of $\mathrm{pH}$ was achieved in $\mathrm{R} 1$ by feeding a variable volume of buffer solution over the period of the experiment (Table 3). The pH was acid due to VFA formation from SWW2, since VFAs are stronger acids (Ka in the order of $10^{-5}$ ) than phenol $\left(\mathrm{Ka}=1.1 \times 10^{-10}\right)$. In the case of $\mathrm{R} 2, \mathrm{pH}$ was stable. In contrast, stable $\mathrm{pH}$ conditions were not achieved in the SSD (Table 3). This reactor started as methanogenic and became acidogenic after $24 \mathrm{~h}$ due to fast growth of acidogens and flushing out of methanogens (sludge replenishing was not allowed in both TSAD and SSR). Better $\mathrm{pH}$ control was therefore achieved in the TSAD.

The $400 \mathrm{~m} \ell$ daily loading (9.7 g DCOD) led to an increment in the DCOD in R1 and SSD, resulting in negative conversion values (Table 3 ), which are merely mathematical artefacts.

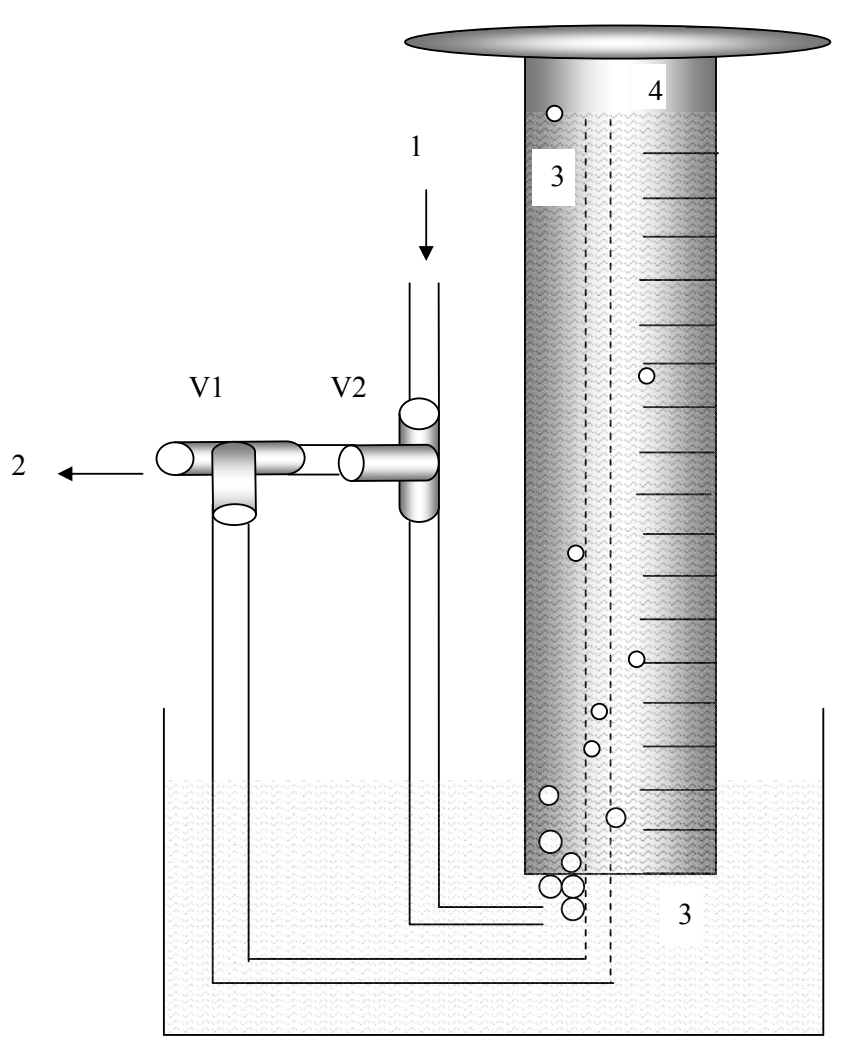

Figure 4

Gas meter prototype designed for measuring gas production. 1. Inlet for gas produced during the experiment; 2. Bi-functional outlet: it can be switched by combining the open/ close positions of both three-way valves (V1 and V2), for 2 purposes, either to raise the barrier solution up to the zero level in the graduated cylinder or to collect a gas sample; 3. Barrier solution; 4. Gas accumulated. Note: the experimentalist can correct the readings of accumulated gas, slightly affected by the water column inside the cylinder, by applying a simple manometric analysis. Alternatively, the water column effect can be considered negligible. 
Similar findings have been reported by Ghosh et al. (1975) and are caused by accumulation of VFAs due to overloading. Contrary to this, in R2 nearly $77 \%$ of the initial DCOD was degraded after 1 day of operation. In this reactor, there was not accumulation of the un-degraded DCOD fraction, which was most probably co-degraded with the diluted load coming from $\mathrm{R} 1$ and adsorbed onto the sludge in R2. Under these conditions, both R1 and SSD were inefficient for DCOD removal.

Hydrolysis of readily biodegradable matter in SSW2 and subsequent formation of organic acids in R1 occurred without inhibition by phenol accumulation (Table 3). In R2, 95\% of organic acids contained in the effluent of R1 were easily reduced within $24 \mathrm{~h}$ and such reduction was linked to an increase in $\mathrm{CH}_{4}$ and $\mathrm{CO}_{2}$ production. The concentration of organic acids in $\mathrm{R} 2$ was below $500 \mathrm{mg}$ acetic acid $\ell^{-1}$, which is a recommended value for stable methanogenic reactors (Dries, 2002). Again, in the case of the SSD, the accumulation of organic acids produced by fast-growing acidogens promoted the disruption of methanogenesis. A low $\mathrm{pH}$ and the yellowishbrown colour were observed (Table 3 ). This reactor was not further analysed due to its failure to biomineralise phenol and readily biodegradable matter in SSW2.

Biomass concentration (SOC) in R1 was not affected by the accumulation of phenol. In R2, there was variability in biomass concentration, probably caused by the detachment of biomass from the packing material due to stirring. In the case of the $\mathrm{SSD}$, biomass concentration was approximately that of R1, indicating that the same operational conditions in both reactors led to similar growth rates of acidogens (Table 3).

\section{Conclusions}

A synthetic wastewater containing a readily biodegradable matter and phenol was treated in a two-stage anaerobic digester (TSAD: acidogenic and methanogenic) and a single-stage digester (SSD). The TSAD produced more biogas; fermented a readily biodegradable organic matter without inhibition by phenol; facilitated the control of acidogenic and methanogenic stages and allowed the dilution of both VFAs and aromatic compounds to avoid methanogenesis inhibition. Batch TSAD is a potential wastewater treatment option to decontaminate streams containing phenol and readily biodegradable organic matter.

\section{Acknowledgements}

We would like to express gratitude to CONACYT for the sponsorship given (Grant 167740).

\section{References}

APHA (1998) Standard Methods for the Examination of Water and Wastewater. American Public Health Association, Washington.

CEN (EUROPEAN COMMITTEE FOR STANDARDIZATION) (1999) EN ISO 11734:1999. Water Quality - Evaluation Of The "Ultimate" Anaerobic Biodegradability Of Organic Compounds
In Digested Sludge - Method By Measurement Of The Biogas Production. European Committee for Standardization, Brussels.

DEMIREL B and YENIGUN O (2002) Two-phase anaerobic digestion processes: a review. J. Chem. Technol. Biotechnol. 77 (7) 743-755.

DIN (DEUTCHES INSTITUT FÜR NORMUNG) (1985) DIN $38414-$ 8:1985. German Standard Methods For The Examination Of Water, Waste Water And Sludge; Sludge And Sediments (Group S); Determination Of The Amenability To Anaerobic Digestion (S 8). Deutches Institut für Normung, Berlin.

ESCHER BI, SNOZZI M and SCHWARZENBACH RP (1996) Uptake, speciation, and uncoupling activity of substituted phenols in energy transducing membranes. Environ. Sci. Technol. 30 (10) 3071-3079.

FEDORAK PM and HRUDEY SE (1984) The effects of phenol and some alkyl phenolics on batch anaerobic methanogenesis. Water Res. 18 (3) 361-367.

GHOSH S, CONRAD J and KLASS DL (1975) Anaerobic acidogenesis of wastewater sludge. J. Water Pollut. Control Federation. 47 (1) 30-45.

HEALY JBJ and YOUNG LY (1979) Anaerobic biodegradation of eleven aromatic compounds to methane. Appl. Environ. Microbiol. 38 (1) 84-89.

HERNANDEZ JE and EDYVEAN RGJ (2008) Inhibition of biogas production and biodegradability by substituted phenolic compounds in anaerobic sludge. J. Hazard. Mater. 160 (1) 20-28.

HERRMANN AP and JANKE HD (2001) Cofermentation of rutin and hesperidin during two-stage anaerobic pre-treatment of highloaded brewery wastewater. Water Res. 35 (11) 2583-2588.

KARLSSON A, EJLERTSSON J and SVENSSON BH (2000) $\mathrm{CO}_{2}$ dependent fermentation of phenol to acetate, butyrate and benzoate by an anaerobic, pasteurised culture. Arch. Microbiol. 173 (5-6) 398-402.

NG WJ, HU JY, ONG SL and AZIZ MA (1999) Effect of acidogenic stage on aerobic toxic organic removal. J. Environ. Eng. 125 (6) 495-500.

NIWA SI, ESWARAMOORTHY M, NAIR J, RAJ A, ITOH N, SHOJI H, NAMBA T and MIZUKAMI F (2002) A one-step conversion of benzene to phenol with a palladium membrane. Sci. 295 (5552) 105-107.

PANOV GI (2000) Oxidation of benzene to phenol by nitrous oxide. Cattech 4 (1) 18-32.

THAUER RK, JUNGERMANN K and DECKER K (1977) Energy conservation in chemotrophic anaerobic bacteria. Bacteriol. Rev. 41 (1) 100-180.

TCHOBANOGLOUS G, BURTON FL and STENSEL HD (2003) Wastewater Engineering Treatment and Reuse (4th edn.) Metcalf \& Eddy Inc, McGraw-Hill, New York.

USEPA (UNITED STATES ENVIRONMENTAL PROTECTION AGENCY) (2008) TRI Explorer [Data file]. URL: http://www.epa. gov/triexplorer/ (Accessed 8 February 2008).

VEERESH GS, KUMAR P and MEHROTRA I (2005) Treatment of phenol and cresols in upflow anaerobic sludge blanket (UASB) process: a review. Water Res. 39 (1) 154-170.

WANG YT, GABBARD HD and PAI PC (1991) Inhibition of acetate methanogenesis by phenols. J. Environ. Eng. 117 (4) 487-500.

WANG YT, SUIDAN MT, PFEFFER JT and NAJAM I (1989) The effect of concentration of phenols on their batch methanogenesis. Biotechnol. Bioeng. 33 (10) 1353-1357.

WINTER J and KNOLL G (1989) Methanogens - Synthrophic dependence on fermentative and acetogenic bacteria in different ecosystems. Adv. Space Res. 9 (6) 107-116. 